Revista Arbitrada Interdisciplinaria KOINONIA

Año V. Vol V. N¹0. Julio - Diciembre 2020

Hecho el depósito de Ley: FA2016000010 ISSN: 2542-3088

FUNDACIÓN KOINONIA (F.K). Santa Ana de Coro. Venezuela.

Eliana Michelle Ordóñez-Granda; Cecilia Ivonne Narváez-Zurita; Juan Carlos Erazo-Álvarez

http://dx.doi.org/10.35381/r.k.v5i10.693

\title{
El sistema financiero en Ecuador. Herramientas innovadoras y nuevos modelos de negocio
}

\section{The financial system in Ecuador. Innovative tools and new business models}

\author{
Eliana Michelle Ordóñez-Granda \\ eliana.ordonez@psg.ucacue.edu.ec \\ Universidad Católica de Cuenca, Cuenca \\ Ecuador \\ https://orcid.org/0000-0001-9099-0156 \\ Cecilia Ivonne Narváez-Zurita \\ inarvaez@ucacue.edu.ec \\ Universidad Católica de Cuenca, Cuenca \\ Ecuador \\ https://orcid.org/0000-0002-7437-9880 \\ Juan Carlos Erazo-Álvarez \\ jcerazo@ucacue.edu.ec \\ Universidad Católica de Cuenca, Cuenca \\ Ecuador \\ https://orcid.org/0000-0001-6480-2270
}

Recibido: 16 de marzo de 2020

Revisado: 10 de abril de 2020

Aprobado: 02 de mayo de 2020

Publicado: 19 de mayo de 2020

\section{RESUMEN}

El sistema financiero representa uno de los pilares fundamentales de la economía del país, razón por la cual se buscó profundizar en el comportamiento de las entidades bancarias más importantes de la ciudad de Cuenca con el objetivo de diseñar estrategias financieras, tecnológicas y contables como mecanismo de generación de valor y rendimientos financieros. La presente investigación se desarrolló empleando un diseño transaccional descriptivo no experimental. Los hallazgos expresan que entre las instituciones financieras existe preocupación por el óptimo desempeño y la eficiencia en sus gestiones administrativas. De forma concluyente, las estrategias innovadoras y la 


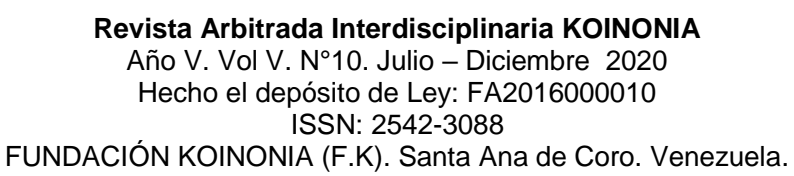

Eliana Michelle Ordóñez-Granda; Cecilia Ivonne Narváez-Zurita; Juan Carlos Erazo-Álvarez

inclusión de modelos de negocios no sólo permiten atender las demandas del mercado financiero actual, sino que se ajusta a las flexibilizaciones de la dinámica económica que atiende a la realidad en que se desarrolla el sistema financiero, permitiéndole así, enfrentar cambios y crisis emergentes como la pandemia por coronavirus (COVID-19).

Descriptores: Instituciones financieras; política financiera; política monetaria; financiación. (Palabras tomadas del Tesauro UNESCO).

\section{ABSTRACT}

The financial system represents one of the fundamental pillars of the country's economy, which is why it was sought to deepen the behavior of the most important banking entities in the city of Cuenca with the aim of designing financial, technological and accounting strategies as a mechanism for generation of value and financial returns. This investigation was developed using a non-experimental descriptive transactional design. The findings express that there is concern among financial institutions about the optimal performance and efficiency in their administrative efforts. In a conclusive way, the innovative strategies and the inclusion of business models not only allow meeting the demands of the current financial market, but also adjusting to the flexibilities of the economic dynamics that attends to the reality in which the financial system develops, permiting, in this way, facing changes and emergent crises such as the coronavirus pandemic (COVID-19).

Descriptors: Financial institutions; financial policy; monetary policy; financing. (Words taken from the UNESCO Thesaurus).

\section{INTRODUCCIÓN}

El sistema financiero desempeña un papel fundamental en el óptimo funcionamiento de la economía, dado que a través del mismo se realizan las diferentes actividades financieras existentes, por lo tanto, la correcta participación de los distintos entes financieros contribuye a elevar el crecimiento económico y bienestar de la población. Bajo este preámbulo, es pertinente mencionar que a mediados de la década de los noventa el Ecuador vivió una crisis financiera sin precedentes, las tasas de interés se habían elevado, en consecuencia también las tasas referenciales se incrementaron, en tanto que, empezó a elevarse la cartera vencida y existía ya una crisis fiscal, esto provocó que las personas comenzaran a retirar dinero de los bancos, disminuyendo su 


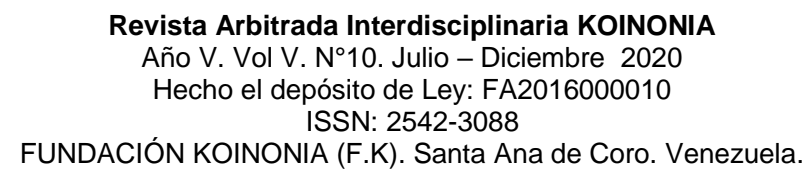

Eliana Michelle Ordóñez-Granda; Cecilia Ivonne Narváez-Zurita; Juan Carlos Erazo-Álvarez

liquidez, por lo que algunas entidades financieras solicitaron créditos al banco central, mientras otras tuvieron que ser liquidadas.

Estos hechos condujeron a una crisis que provocó el cambio de moneda, dando paso a la adopción de dólar de los Estados Unidos de Norte América. Ante estos precedentes, el autor (Llistar, 2002), refiere que las medidas económicas expresadas en el Consenso de Washington (CW) son insuficientes, por lo cual suma a este manifiesto tres nuevos aspectos: mayor transparencia en instituciones de carácter público, así como en

empresas y bancos; mayor supervisión del Estado al sector financiero (fondos de inversión y paraísos fiscales) y por último estrategias para el sector financiero que permitan una autonomía progresiva y más cuidadosa.

En base a este análisis preliminar del sistema financiero, la presente investigación tiene como objetivo diseñar estrategias contables, financieras y administrativas para el sistema financiero ecuatoriano como mecanismo de generación de valor y rendimientos financieros.

\section{Referencial teórico}

\section{Funcionamiento y estructura del sistema financiero ecuatoriano}

El sistema financiero está conformado por instituciones públicas y privadas con el fin de captar los ahorros de las personas y colocar estos fondos a través de créditos para así generar rendimientos financieros que contribuyan tanto a las instituciones de intermediación financiera como a sus socios o cliente, esta canalización de recursos juega un papel importante en el progreso económico de los países debido a que el flujo de dinero procedente de los excedentes de dinero de las personas se convierten en créditos destinados a personas que necesitan de estos recursos (Romero, 2015). En base a este concepto el sistema financiero sirve como un mediador entre las personas con excedentes de dinero y aquellas que no tienen suficientes recursos para financiar sus actividades, para lo cual las instituciones financieras desempeñan la función de intermediarias entre estos usuarios, poniendo a su disposición activos financieros que permiten mantener la riqueza de estos. 


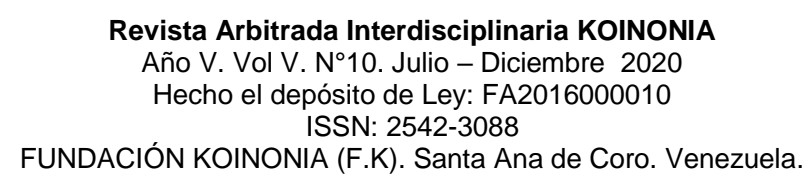

Eliana Michelle Ordóñez-Granda; Cecilia Ivonne Narváez-Zurita; Juan Carlos Erazo-Álvarez

Con el financiamiento obtenido a través del sistema financiero, emprendedores, compañías o instituciones gubernamentales realizan inversión productiva generando un mayor desarrollo económico. El sistema financiero cumple múltiples funciones: captar y promover el ahorro, canalizándolo hacia diferentes agentes económicos; facilita el intercambio de bienes y servicios; gestiona medios de pago y procura el crecimiento económico de la población.

En Ecuador el sistema financiero está formado por cooperativas de ahorro y crédito, mutualistas y otras instituciones financieras, aunque el mayor segmento de los activos se concentra en la banca privada. El sistema bancario ecuatoriano es regulado y controlado por la Superintendencia de Bancos y Seguros (SBS), cuya misión es resguardar los intereses de los clientes y el fortalecimiento del sistema, todo este conjunto de instituciones y entes de regulación tienen como objetivo facilitar y asegurar el movimiento de dinero y el sistema de pagos dentro de la economía, es decir se encarga de la compra y venta de los activos en los mercados financieros.

A partir del año 2000 el Ecuador atravesó una etapa de cambio y transición en su sistema financiero, fue evidente el crecimiento que vivió este sector, en el año 2011 se consideró en la Agenda de la Política Económica para el Buen Vivir una mayor participación de la banca pública dentro de la estructura financiera nacional. Bajo estos lineamientos la banca empezó a adquirir un rol principal dentro de la economía ecuatoriana inyectando una gran cantidad de fondos en diferentes sectores productivos. Para diciembre del 2017 solo en la provincia del Azuay los saldos de captaciones en depósitos de ahorro representaron el $25.20 \%$ y en depósitos a plazo fijo el $30.40 \%$, en cuanto a colocaciones se cerró el año con un monto de USD 2.535.1 millones de dólares, $2.1 \%$ más que el año 2016, su mayor concentración se presentó en el microcrédito con el 18.6\%, seguido del crédito para vivienda con el $7.2 \%$ (Superintendencia de Bancos, 2017).

Después de la crisis que atravesó el país en 1999, se consolidó un sistema financiero estable y con mayor control, demostrando un crecimiento continuo, esta seguridad renovó la confianza de los ecuatorianos quienes en las últimas décadas han 


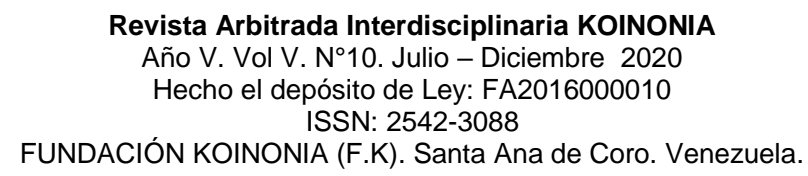

Eliana Michelle Ordóñez-Granda; Cecilia Ivonne Narváez-Zurita; Juan Carlos Erazo-Álvarez

incrementado su preferencia por ahorrar y depositar su capital en cuentas a plazo fijo, esto a su vez acrecentó la capacidad de endeudamiento de la población quienes ahora gozan de las garantías adecuadas en el sistema financiero. Con estas garantías se generó un importante incremento en las utilidades del sistema financiero, logrando incluso almacenar provisiones para cubrir potenciales riesgos de cartera.

Hasta el año 2014 se mantuvo una tendencia creciente en los depósitos, sin embargo, en el año 2015 la economía ecuatoriana entró en recesión y el crecimiento registrado fue mínimo reduciendo los depósitos en un -10.59\%, ya para el año 2016 se recuperó el montó en los depósitos e incluso se superó el valor registrado dos años atrás, en el año 2017 se registró un monto máximo histórico de depósitos por un valor de USD 34.805,3 millones, demostrando así que el sistema es sólido y no se ven señales de riesgo (Superintendencia de Bancos, 2018).

El sector financiero se ha ido consolidando, luego de la difícil situación económica que atravesó a finales del siglo pasado y la adopción de la dolarización; Además, a pesar de la serie de eventos producidos por las dificultades financieras, el bajo precio del barril de petróleo, así como las variaciones de los precios de las divisas que han complicado la capacidad de exportación del país, estas instituciones han tratado de "adaptarse a los nuevos escenarios económicos adversos y realinear sus estrategias para mantener sus niveles de rentabilidad, solvencia y liquidez" (Taimal, 2016, p.4).

\section{Administración de activos y pasivos en el sistema financiero ecuatoriano}

El sistema financiero está conformado por distintos elementos entre los que se encuentran:

1. Activos o instrumentos financieros.

2. Intermediarios financieros.

3. Mercados financieros.

Al respecto, (Patiño, 2014) afirma que los instrumentos financieros son servicios que originan una obligación para quien los adquiere y genera un derecho para el propietario. Su origen se deriva de la necesidad de la adquisición de liquidez por parte del emisor a 


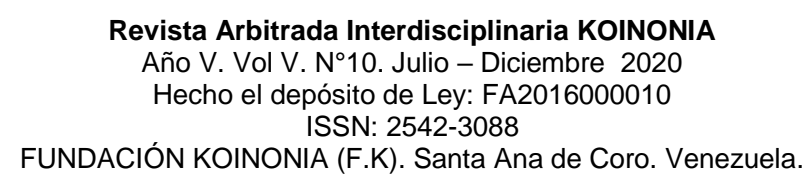

Eliana Michelle Ordóñez-Granda; Cecilia Ivonne Narváez-Zurita; Juan Carlos Erazo-Álvarez

cambio de percibir rendimientos pecuniarios a través de mercados financieros legítimamente instaurados. Las dos funciones principales de los activos financieros son:

1. Transferir fondos de aquellos que tienen un excedente para invertir, hacia aquellos que los necesitan para invertirlos en activos tangibles.

2. Transferir fondos de forma en la que se redistribuya el inevitable riesgo asociado con el flujo de efectivo, el cual se genera por los activos tangibles, entre aquellos que buscan y aquellos que proporcionan los fondos.

Los instrumentos financieros sirven para invertir y financiar, su función es proporcionar la conservación y disposición de los recursos financieros a los dependientes económicos. Existen dos modelos de instrumentos financieros: un modelo de costo amortizado para los instrumentos financieros básicos y un modelo de valor razonable con cambios en los resultados para las inversiones en acciones que tienen un precio público. Según (Trujillo, 2014), los instrumentos financieros básicos se clasifican en:

Activo: efectivo (divisas); cuentas por cobrar; préstamos; inversiones en títulos de deuda; inversiones en títulos de capital no cotizados.

Pasivo: proveedores de bienes y servicios y préstamos.

En este contexto, el sistema de bancos privados, como integrante del Sistema Financiero Nacional (Público y Privado) fiscalizado por la Superintendencia de Bancos para junio del año 2018 concentró el 82,73\% de los activos; 85,58\% de la cartera bruta; $86,53 \%$ de los pasivos; $88,17 \%$ de los depósitos del público; $60,68 \%$ del patrimonio y $69,38 \%$ de los resultados. El crecimiento referido de USD 1.833,23 millones, fue consecuencia del crecimiento de la cartera de créditos en USD 3.359,10 millones, la reducción de los fondos disponibles en USD 1.178,56 millones y de las inversiones en USD 425,81 millones. (Superintendencia de Bancos, 2018). Mediante el ofrecimiento de distintos productos financieros la banca privada ha buscado gestionar de manera óptima sus activos, a través de:

1. Créditos: que sirven para financiamiento y ampliación de los negocios ya sea con capital de trabajo o con la compra de activos fijos. 


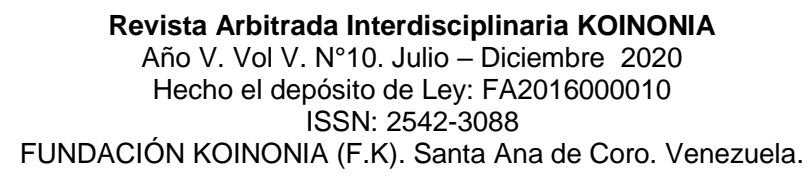

Eliana Michelle Ordóñez-Granda; Cecilia Ivonne Narváez-Zurita; Juan Carlos Erazo-Álvarez

2. Créditos inmobiliarios: que hacen viables operaciones productivas, ajustando los pagos de acuerdo al ciclo de producción de la empresa, y están diseñados para costear los proyectos de construcción de forma eficaz, con continuidad y facilitar hipotecas para la adquisición de inmuebles destinados a oficinas, locales, consultorios, etc.

3. Tarjetas de crédito: facilitan la adquisición de bienes en línea tanto dentro del país cuanto fuera de él, a más de ello este producto permite diferir el pago de estos consumos.

4. Distribuidor - proveedor: está enfocado en dar créditos para cubrir compras y pagos a proveedores, este producto reemplaza el financiamiento directo y la falta de flujo de caja.

5. Cartas de garantía: avalan al beneficiario el pago de un valor fijo, se cuenta con el respaldo financiero del Banco para garantizar sus operaciones, sin afectar su flujo de liquidez.

6. Garantía mandataria: este producto tiene como objetivo asegurar los pagos o garantizar los contratos de las compañías que efectúan actividades de comercio.

7. Tarjeta empresarial: concede a los franquiciados o intermediarios de las compañías clientes, la ventaja de adquirir insumos, productos o materiales que la empresa distribuye.

8. Depósitos a plazo fijo: son operaciones financieras que mantienen los recursos monetarios inmovilizados por un periodo de tiempo a cambio de una renta financiera fija o variable.

9. Certificados de ahorro: son inversiones a corto plazo de 1 a 29 días, que ofrecen rentabilidad con total seguridad, con una tasa de interés estipulada al momento de la negociación.

A través de la gestión efectiva de los activos, según datos de la Superintendencia de Bancos, el sistema de bancos privados, presentó para junio de año 2018 en relación a junio del año 2017, un aumento en la rentabilidad, calidad de activos, cobertura e intermediación financiera; disminuyó la morosidad y la relación de los gastos operativos 


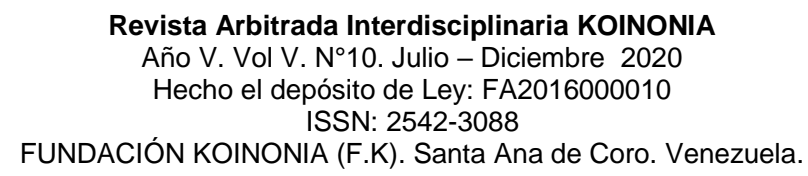

Eliana Michelle Ordóñez-Granda; Cecilia Ivonne Narváez-Zurita; Juan Carlos Erazo-Álvarez

y de personal frente a los activos promedio. Por el contrario, registró decrementos en los niveles de liquidez y de la solvencia, aunque esta última se mantuvo por encima del mínimo legal. (Superintendencia de Bancos, 2018).

\section{Comportamiento de las tecnologías de crédito en Ecuador}

El comportamiento crediticio de quienes acceden a un crédito, la forma en la que se desenvuelve la economía que condiciona la respuesta de los usuarios de un crédito y las normas que reglamentan y controlan el sistema financiero, determinan el riesgo de cada operación ejecutada en la banca. La observación del comportamiento de variables como la concentración crediticia, morosidad, nivel de provisiones, sumados a los riesgos antes mencionados, sirven para evaluar el grado de respuesta de los intermediarios financieros ante posibles situaciones de alerta que pueden presentarse en un momento dado en los sujetos de crédito y en las actividades económicas a las que financian, a fin de evitar un detrimento de su situación financiera.

Basados en los datos de la Superintendencia de Bancos y en lo referente a la cartera de crédito se puede colegir que, el sistema financiero acogió un total de 25 sectores económicos en el año 2017, en la figura 1 se observa cuáles son los porcentajes y los sectores a donde se ha destinado estos fondos y como han variado los porcentajes en comparación a los periodos 2016 - 2017. 


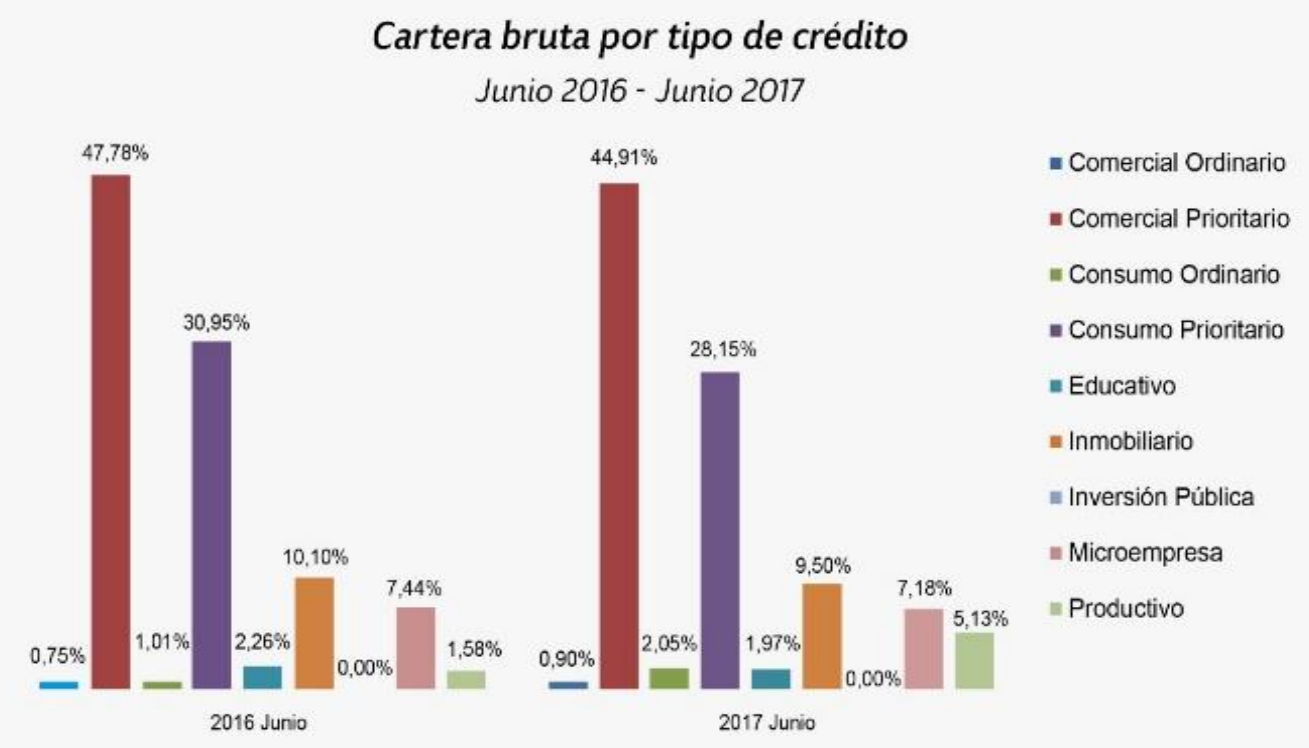

Figura 1. Cartera de crédito por sectores productivos. Fuente: Superintendencia de bancos (2016-2017).

Para el período 2016 - 2017 se evidenció un crecimiento de 14,7\% en la cartera bruta, alcanzando según datos de la Superintendencia de Bancos un total de 21.443 millones de dólares, siendo el segmento comercial prioritario al que se le otorgó la mayor parte del crédito, en segundo lugar, está el consumo prioritario con el $28,15 \%$. Es importante resaltar que en este periodo se logró reducir el índice de morosidad de 4,35\% a 3,35\%. Según la información obtenida de la Asociación de Bancos Privados del Ecuador, se registró un saldo de créditos de 26.033 millones de dólares, en comparación al periodo analizado en párrafos anteriores (2016 -2017), dando como resultado un crecimiento del $15 \%$, este incremento se da como respuesta a un cambio en las expectativas de los empresarios y los consumidores sobre la situación del país.

Estas cifras muestran que la banca privada ha empezado a confiar en el país recurriendo incluso al uso de sus reservas para otorgar créditos. En este periodo también se registra un mejor desempeño en los créditos productivos, duplicando su cartera de USD 976 millones a 2042 millones. En este periodo también se redujo la 


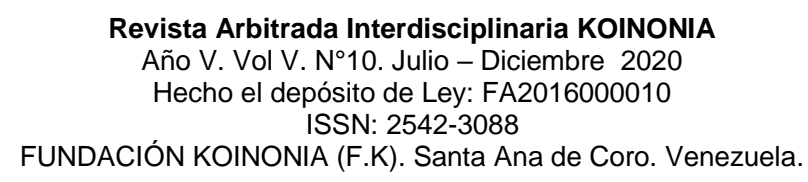

Eliana Michelle Ordóñez-Granda; Cecilia Ivonne Narváez-Zurita; Juan Carlos Erazo-Álvarez

tasa de interés del $11,5 \%$ al 10,1\%; así mismo, el crédito de consumo creció un $17,3 \%$ en relación al año anterior.

Según los datos estadísticos publicados sobre la realidad del Ecuador con corte a diciembre del año 2017, "se totalizaron 2.286,5 millones de transacciones realizadas a través de la banca, de las cuales, en su mayoría, esto es 1.667,4 millones de transacciones fueron realizadas de manera electrónica y 619 millones de manera directa en las instituciones (Instituto Nacional de Estadística y Censos, 2017). En ese mismo estudio, se destaca que entre los últimos 6 años (2011 - 2017) el promedio de crecimiento fue del $20 \%$ en donde el $74,43 \%$ corresponden a transacciones electrónicas y sólo un $25,57 \%$ a transacciones financieras realizadas en una oficina, esto se debe a que la falta de alfabetización digital está en disminución, cerrando el año 2016 en $11,45 \%$ mientras que 6 años atrás era del 29,22\%.

Estos resultados, incentivan al Ecuador a crear o fortalecer nuevos canales digitales para aumentar sus transacciones electrónicas e incrementar la cobertura en las personas no bancarizadas. Según el (Instituto Nacional de Estadística y Censos, 2013), cerca de 6 de cada 10 familias en el Ecuador están en capacidad de ahorrar y retirar dinero en base a sus ingresos monetarios, razón por la cual es importante que el sistema financiero se apoye en la tecnología y busque expandir sus canales digitales con la finalidad de captar la atención de los clientes ofreciéndoles herramientas que se ajusten a sus necesidades, facilitando y reduciendo los trámites financieros.

En la actualidad las regulaciones del Ecuador no permiten crear una cuenta bancaria sin la presencia física de documentos como la copia de la cédula de identidad, ruc o pasaporte, así como la copia de una planilla de servicios básicos, incluso se creó un tipo de cuenta de menor restricción denominada cuenta básica aunque la misma todavía mantiene similares restricciones (Superintendecia de Bancos y seguros del Ecuador, 2011).

Esta realidad pone de manifiesto la necesidad de que las instituciones financieras promuevan programas de educación financiera que contribuyan a que los ciudadanos conozcan sobre las principales características, costos y riesgos tanto de los productos 


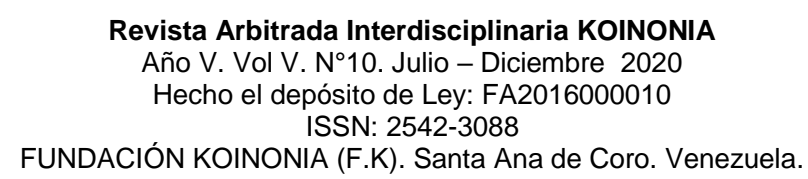

Eliana Michelle Ordóñez-Granda; Cecilia Ivonne Narváez-Zurita; Juan Carlos Erazo-Álvarez

como de los servicios financieros con el propósito de que tomen decisiones adecuadas. En Brasil se pudo evidenciar que disponer de programas de educación financiera minimiza la brecha de inclusión financiera, contribuyendo a incrementar la alfabetización y la competencia financiera de la sociedad (Birochi \& Pozzeben, 2016).

\section{Herramientas innovadoras y modelos de negocio para la generación de valor y rendimientos financieros en el sistema financiero}

En la actualidad el avance tecnológico ha favorecido las actividades operativas tanto de las personas naturales como jurídicas, debido a que, gracias a los sistemas informáticos, aplicaciones e incluso el uso de celulares han minimizado los engorrosos trámites, haciendo más fácil el acceso a los servicios bancarios. En países como Brasil, los corresponsales bancarios conectan alrededor de 45 millones de personas al sistema financiero (Acosta-Véliz, Coronel-Pérez \& Bermúdez-Gallegos, 2018).

Las entidades financieras con el fin de apoyar el desarrollo de actividades productivas y cotidianas, han creado ventanillas especializadas, VIP, cash management, cajeros automáticos, banca virtual, banca electrónica, banca móvil, entre otros. Sin embargo, Alide (2014) sostiene que el nivel de bancarización es muy bajo en América Latina y el Caribe, siendo un reto para la banca incrementar nuevos servicios financieros, implementar productos innovadores con costos que resulten competitivos y accesibles para que más personas hagan mayor uso de estos medios.

En el caso de Ecuador entre las estrategias empleadas para promover la inclusión financiera se han creado los corresponsales no bancarios, una herramienta que cambió el mercado financiero que promovió la participación de sectores de la población apartados y desatendidos, originando emprendimientos que acercan a los usuarios con la banca y benefician al intermediario, generando costes muy inferiores al de una agencia bancaria (Méndez, 2008).

En un mundo cada vez más acelerado el poder realizar transacciones como depósitos, retiros y pagos de servicios de manera rápida facilita el desarrollo de las actividades cotidianas tanto de las empresas como de las personas naturales, razón por la cual los 


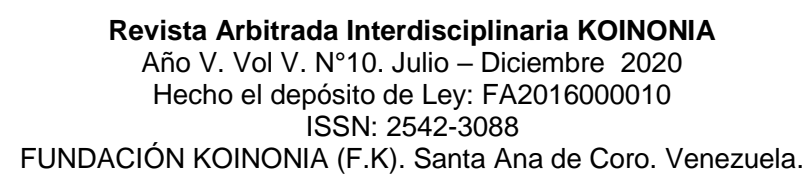

Eliana Michelle Ordóñez-Granda; Cecilia Ivonne Narváez-Zurita; Juan Carlos Erazo-Álvarez

corresponsales no bancarios representan una herramienta innovadora que facilita los sistemas de negocios al ubicar sus agencias dentro de zonas urbanas logrando una mayor bancarización regional. En consecuencia, la tecnología se ha convertido en el factor más importante del sistema financiero, por cuanto permite al usuario la oportunidad de utilizarla de acuerdo a sus necesidades con la calidad y seguridad a menores costos (Kumar, Nair, Parsons \& Urdapilleta, 2006).

Estas innovaciones del sistema financiero han logrado que los nuevos modelos de negocios aporten al financiamiento de la banca reduciendo de forma significativa los costos de infraestructura, equipos y personal que suelen ser necesarios al generar una sucursal bancaria, a más de esto dado que se pueden realizar varias transacciones sin necesidad de acudir al banco se ha logrado una descongestión en los mismos procurando que los usuarios acudan a ellos en busca de servicios especializados.

\section{Modelo de inclusión financiera a través de corresponsales no bancarios}

El sistema financiero contribuye al desarrollo de las familias brindando la posibilidad de adquirir bienes pagaderos en un mediano plazo o de generar rendimientos financieros a través de sus ahorros (Peña \& Vázquez, 2012). Sin embargo, en zonas rurales o en sitios alejados del núcleo de una metrópolis el acceso de la población a las entidades financieras se ve limitado debido a que el volumen de transacciones no compensa los costos de apertura y mantenimiento de una agencia bancaria (De-Olloqui, Andrade \& Herrera, 2015). Por tal razón, el sistema financiero en varios países de América Latina diseñó un modelo de inclusión financiera para atender dicha necesidad, llamada corresponsal no bancario, corresponsales, corresponsalías, o agentes bancarios (Guerra, 2015).

Por otro lado, (Cepeda-Cobos, 2014), define al corresponsal no bancario, como "un tercero contratado por una institución financiera con el propósito de prestar servicios a sus clientes y usuarios" (p.1). Este "tercero" puede ser un supermercado, una farmacia, una agencia de envíos, que se adapte a las políticas que establece el banco para garantizar la seguridad y confianza de sus usuarios, una de las características de este 


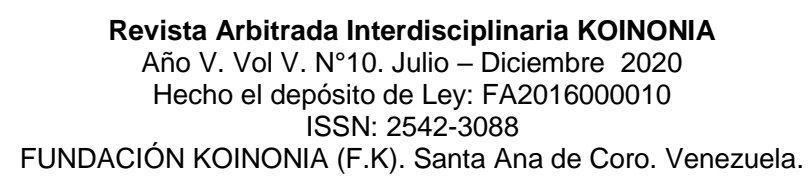

Eliana Michelle Ordóñez-Granda; Cecilia Ivonne Narváez-Zurita; Juan Carlos Erazo-Álvarez

nuevo modelo de negocio es ubicarse en lugares que faciliten el acceso del usuario y a su vez representen una inversión menor a la que implicaría estructurar una sucursal bancaria, aunque esto no quiera decir que deje de brindar un acceso óptimo a una amplia gama de servicios financieros, todo esto a un precio razonable y cumpliendo con las políticas del banco en todos los aspectos de confianza, seguridad y tranquilidad para el usuario (Cáceres-Larreátegui, Torres-Mejía \& Briones-Arteaga, 2019).

Por otro lado, (Rodríguez, 2017), propone un modelo que promueve la inclusión financiera con responsabilidad social aplicable a entidades bancarias. En el cual refleja dos vías de desarrollo de la inclusión financiera, una mediante la masificación de microcréditos y la segunda mediante la potenciación de corresponsales no bancarios. Varios autores en la literatura han tratado de esquematizar el modelo de negocios de los corresponsales en distintos contextos de estudio. Así (Leonardi, Bailey, Diniz, Sholler, \& Nardi, 2016), proponen un modelo en donde integra la entidad financiera pública o privada con la red de tiendas, bancos comunitarios, y oficinas postales para ofrecer al cliente los diversos servicios que necesita la comunidad.

Las empresas de servicio a través de las entidades financieras públicas o privadas facilitan el pago de las facturas mensuales de agua, luz, telefonía, internet a través de los distintos tipos de corresponsales como tiendas, oficina postal, bancos de barrio.

La red integradora es la mediadora entre los corresponsales y la entidad financiera, y ofrece el soporte técnico necesario ante alguna eventualidad. Por otro lado, (AcostaVéliz, Coronel-Pérez \& Bermúdez-Gallegos, 2018), detallan los servicios que se pueden gestionar a través de los corresponsales no bancarios (CBN) en Ecuador, siendo estos diversos en atención a beneficiar al cliente, siendo atendido en horarios ajustados a sus necesidades, gestionando operaciones bancarias en su contexto social.

La banca debe seguir innovando y brindando nuevos servicios a través de los corresponsales no bancarios, ya que estos aportan en gran medida a que los productos financieros tengan menor costo de inversión entre infraestructura y los equipos necesarios, lo que proporciona rentabilidad a la banca. La inclusión es un objetivo clave, los emprendimientos que conlleven la conversión a corresponsales deben verse 


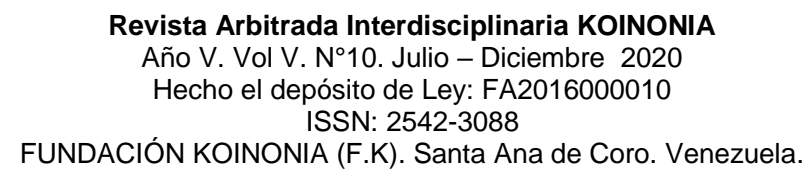

Eliana Michelle Ordóñez-Granda; Cecilia Ivonne Narváez-Zurita; Juan Carlos Erazo-Álvarez

incentivados para que los factores de responsabilidad social se vean evidenciados en dichos negocios y así generar un mayor crecimiento de los CNB en el Ecuador como reflejo del apoyo al emprendedor ecuatoriano.

\section{MÉTODO}

La presente investigación se desarrolló desde una perspectiva descriptiva, buscando ampliar y profundizar sobre la problemática respecto a los sistemas financieros, se empleó un diseño transaccional no experimental (Hernández, Fernández, \& Baptista, 2014). Para la recolección de datos se empleó técnicas e instrumentos de investigación como la entrevista y encuesta, por medio de cuestionarios que sirvieron de guía para el levantamiento de información relevante. El universo de estudio lo conformaron 6 instituciones financieras localizados en la ciudad de Cuenca (Zhañay-Soliz, ErazoÁlvarez \& Narváez -Zurita, 2019).

\section{RESULTADOS}

Análisis de eficiencia y desempeño de la gestión administrativa: las instituciones financieras manifiestan su preocupación por el óptimo desempeño en sus gestiones administrativas. Una eficiente dirección, planificación y organización se reflejan en el logro de objetivos institucionales, así como en precisar oportunidades de mejora a nivel de innovación y ventajas competitivas. En los resultados de la encuesta se aprecia que el $83,33 \%$ de las entidades bancarias realizan un análisis mensual de su desempeño y el $16,67 \%$ lo hace de forma trimestral.

Estrategias para promover el ahorro: el 100\% de las instituciones financieras encuestadas coinciden en que aplican estrategias encaminadas a promover y fomentar el ahorro en los clientes, por considerarlo clave en el desarrollo de la economía familiar y de los países, al constituir la principal fuente de recursos para financiar la inversión o proyectos.

Manejo de recursos económicos: cabe mencionar que la gerencia moderna, incluye entre sus competencias al liderazgo; siendo esta la capacidad que tiene el gerente de 


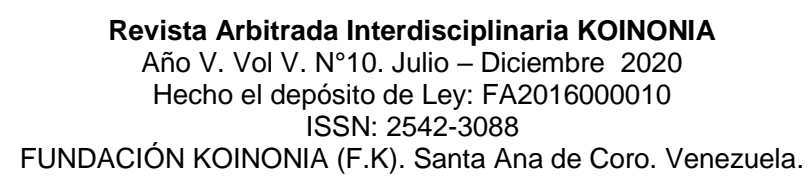

Eliana Michelle Ordóñez-Granda; Cecilia Ivonne Narváez-Zurita; Juan Carlos Erazo-Álvarez

influir en el comportamiento del grupo, la toma de decisiones, la organización, la formación, formación profesional, administración de recursos, entre otros aspectos. En cuanto a la responsabilidad sobre los recursos económicos y financieros de la banca, más de la mitad de los encuestados (66.6\%) refieren que no es competencia exclusiva del gerente, mientras que el resto (33.3\%) afirma que corresponde al gerente.

Supervisión de la gestión: La Superintendencia de Bancos es responsable de supervisar la actividad individual y consolidada de los integrantes del sistema financiero y demás personas, operaciones o entidades que mandan las leyes. Para el ejercicio de estas atribuciones contará con independencia operativa, procesos transparentes y recursos adecuados para el desempeño de sus funciones. El $100 \%$ de las entidades encuestadas afirmaron que la Ley de supervisión de los procesos de gestión de recursos financieros por parte de la Superintendencia de Bancos que rige a las instituciones financieras facilita la evaluación de la gestión y administración adecuada de recursos.

Relación entre los montos captados y la colocación de fondos por parte de los clientes: Es indudable que existe una relación directa entre los montos captados de las instituciones y las necesidades de colocación de los usuarios, por lo tanto, más de la mitad de los encuestados (66.6\%) consideran que esta relación directa es promedio, mientras que el $33.3 \%$ considera que la relación es alta.

Análisis de solvencia y liquidez: el $83,33 \%$ de las instituciones financieras encuestadas indican que siempre realizan análisis de solvencia y liquidez para medir la capacidad que tiene la institución de hacer frente a todos sus compromisos financieros en un futuro no muy lejano, solo el $16.67 \%$ lo realiza de manera ocasional.

Preferencia en la otorgación de créditos: el $50 \%$ de los encuestados refiere que los créditos se otorgan por igual, tanto al sector comercial como al de producción; el $33,33 \%$ coincide en que no existe preferencia por un sector en especial sino por el contrario se brinda atención a todos los sectores por igual, tan solo el 16,67\% afirma que existe una preferencia por el sector productivo. 


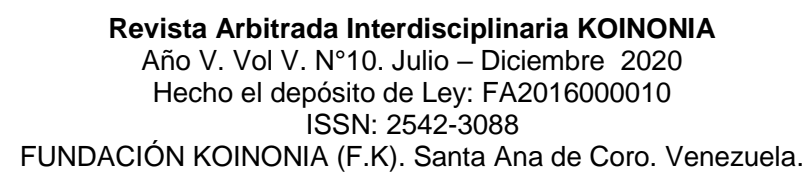

Eliana Michelle Ordóñez-Granda; Cecilia Ivonne Narváez-Zurita; Juan Carlos Erazo-Álvarez

Planificación estratégica y financiera: el 100\% de las entidades encuestadas coincidió en que siempre realizan una planificación estratégica como base para el cumplimiento de los objetivos institucionales, para posesionarse en el mercado y obtener ventajas competitivas.

Inclusión de la banca virtual: el $83,33 \%$ de las entidades bancarias coinciden en que el avance tecnológico y la creación de una aplicación móvil favoreció el uso de la banca virtual, agilitando los trámites bancarios, solo el $16,67 \%$ considera que el crecimiento ha sido medio.

Políticas de administración financiera: las entidades bancarias encuestadas afirmaron en un $83,33 \%$ que las políticas de administración financiera son claras y están definidas de acuerdo a los lineamientos requeridos por cada institución e involucran a todos los colaboradores, mientras que, el $16,67 \%$ considera que son específicas.

Evaluación del desempeño de los funcionarios financieros: el 100\% de los encuestados afirma que la institución evalúa el desempaño de los funcionarios financieros, con el objetivo de valorar el rendimiento de los mismos y descubrir posibles problemas de productividad.

Incidencia de la banca en el desarrollo económico: el 66,66\% de los encuestados considera que la incidencia de la banca en el desarrollo económico del país es alta, mientras que el $33,33 \%$ afirma que es media.

Recuperación de cartera: el $83,33 \%$ de los encuestados afirma que los créditos otorgados por la institución son cancelados en un lapso de entre 1 y 3 años mientras que el 16,67\% afirma que el lapso es superior a 3 años, un periodo más largo conlleva a una menor cancelación de créditos, sin embargo, puede llevar a una pérdida por un mayor tiempo.

Incremento de los activos: el $83.3 \%$ de las entidades bancarias tuvo un incremento considerable en los activos, mientras que el resto (16.67\%) afirma que su incremento fue bajo.

Preferencia del usuario para el contacto: en cuanto a la preferencia del usuario para la comunicación con el banco, el $66.6 \%$ considera que el canal de comunicación es de 


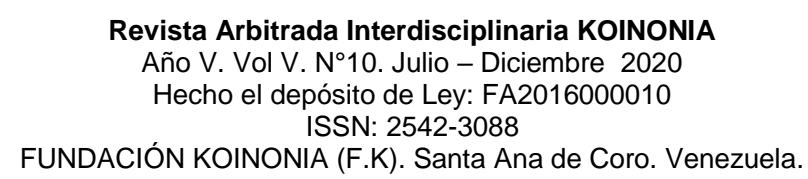

Eliana Michelle Ordóñez-Granda; Cecilia Ivonne Narváez-Zurita; Juan Carlos Erazo-Álvarez

manera personal, mientras que el 33.3\% refiere que mantiene la comunicación con el cliente de manera virtual. La experiencia digital ha creado comodidad y conveniencia; por un lado, esta es una forma de proporcionar información esencial en tiempo real a los clientes de forma personalizada, pero al mismo tiempo hay resistencia de los consumidores a la idea de automatizar sus transacciones financieras, y estos prefieren el trato humano para realizar ciertas operaciones.

Requerimientos para la solicitud y aprobación de un crédito: el 100\% de los encuestados afirma que la institución ha flexibilizado los requisitos para la solicitud y aprobación de los créditos, con el objetivo de alcanzar un proceso crediticio eficiente evitando las demoras y los papeleos que provocan clientes insatisfechos.

Banco del Austro: El 55\% del activo del banco se encuentra en cartera de créditos, un $18 \%$ del activo está como recursos disponibles para su colocación a través de créditos a los clientes, $19 \%$ del activo lo conforman las inversiones, un $5 \%$ representa otros activos. En relación a la cuenta del pasivo, los fondos disponibles representan el $21 \%$ de las obligaciones con el público. En el patrimonio se puede observar la falta de reservas. El $72 \%$ del patrimonio es capital social. Se tiene un superávit por valuaciones del $10 \%$, lo cual revela una revaluación de las propiedades y equipo pertenecientes a la Institución.

Banco Guayaquil: el $63 \%$ del activo está conformado por la cartera de créditos el $18 \%$ del activo como fondos disponibles para la colocación de créditos y hacer frente a las obligaciones con el público. Un $12 \%$ del activo lo representan las inversiones. En cuanto al Pasivo, un $82 \%$ está formado por obligaciones con el público, un $13 \%$ de obligaciones financieras. El $73 \%$ de patrimonio se conforma por el capital social. La cuenta reservas representa un $11 \%$ del patrimonio, así como los resultados de ejercicios anteriores los cuales conforman el $15 \%$.

Banco Pacífico: Un 67\% del activo lo representan la cartera de créditos, un 14\% del activo son inversiones, el $9 \%$ del activo en fondos disponibles, otros activos representan un $5 \%$ del total. Las obligaciones con el público representan el $84 \%$ del pasivo. El capital social representa un $62 \%$ del patrimonio, siendo las reservas lo más relevante 


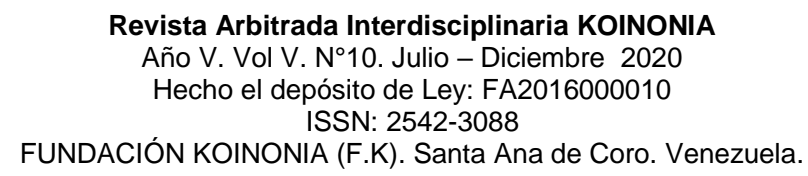

Eliana Michelle Ordóñez-Granda; Cecilia Ivonne Narváez-Zurita; Juan Carlos Erazo-Álvarez

con un $18 \%$ asegurando la posibilidad de hacer frente a obligaciones de corto plazo en caso de ser necesario. La revaluación de inversiones o de activos fijos representa un $6 \%$ del total del patrimonio. Así como un $14 \%$ del mismo está formado por los resultados anteriores.

Banco Pichincha: el $61 \%$ del activo está formado por la cartera de crédito, un $14 \%$ del activo como fondos disponibles, el $7 \%$ del activo se clasifica como otros activos. El $88 \%$ del pasivo son obligaciones con el público. El 64\% del patrimonio está conformado por el capital social, el $15 \%$ de reservas para hacer frente a obligaciones inmediatas, así como un $11 \%$ representado por los resultados anteriores.

Coop. Jep: el 74\% de los activos está conformado por inversiones y no se tiene cartera de créditos, la cooperativa está especializada en inversiones y no en colocación de créditos, el $97 \%$ de los pasivos son las obligaciones con el público. Del patrimonio un $57 \%$ se conforma por reservas y un $32 \%$ por el capital social.

Coop. Jardín Azuayo: la cooperativa tiene como principal giro del negocio la colocación de créditos, observándose que el $74 \%$ de sus activos se concentran en la cartera de créditos, el $12 \%$ de los activos como fondos disponibles. Las obligaciones con el público representan un $88 \%$ del pasivo, el $8 \%$ son obligaciones financieras. E $67 \%$, del patrimonio está conformado por reservas, el $24 \%$ de patrimonio es capital social, así como un 9\% de los resultados anteriores. 


\section{PROPUESTA}

A partir de los resultados obtenidos se propone diseñar estrategias financieras, tecnológicas y contables para el sistema financiero ecuatoriano, con el propósito de generar valor y rendimientos financieros.

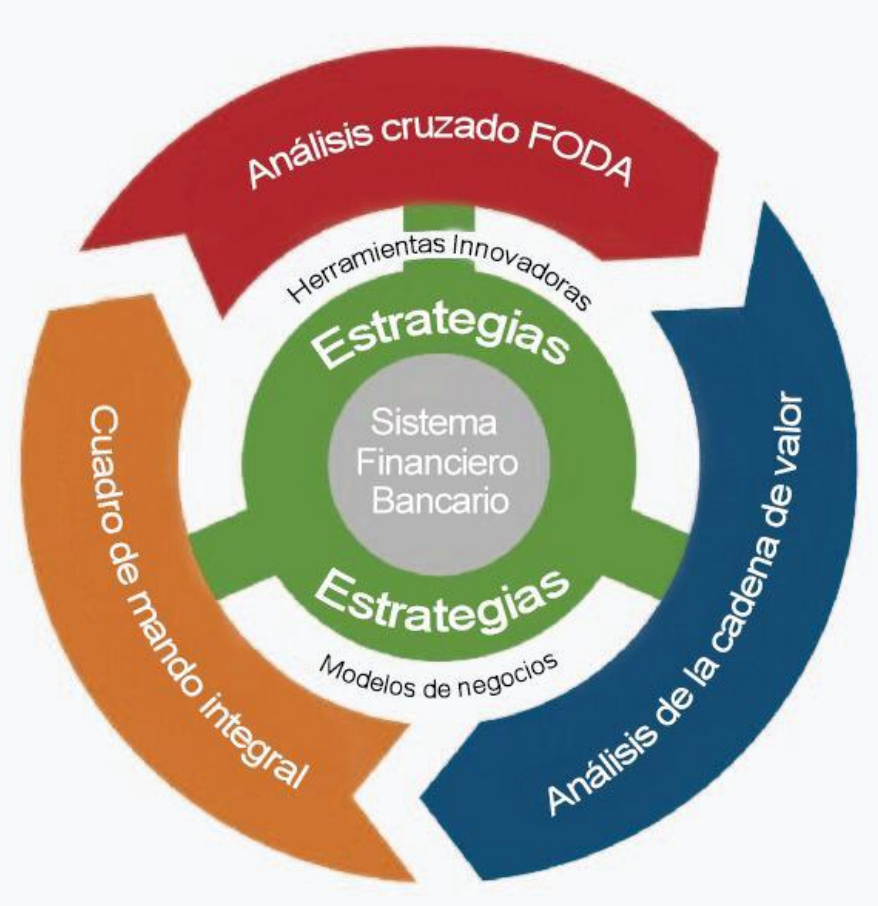

Figura 2. Estrategias financieras, tecnológicas y contables

Como primera estrategia se procede a realizar un análisis cruzado FODA, con el objeto de identificar las fortalezas y oportunidades, que permitan a las entidades financieras afrontar las debilidades y amenazas, solventando las deficiencias y enfocándose en factores que representan un mayor impacto para la entidad, obteniendo así un eficaz, eficiente y óptimo desempeño financiero. 
Revista Arbitrada Interdisciplinaria KOINONIA

Año V. Vol V. №10. Julio - Diciembre 2020

Hecho el depósito de Ley: FA2016000010

ISSN: 2542-3088

FUNDACIÓN KOINONIA (F.K). Santa Ana de Coro. Venezuela.

\begin{tabular}{|c|c|c|}
\hline Eliana Michelle Ordóñez-C & Fortalezas & Debilidades \\
\hline $\begin{array}{c}\text { Análisis cruzado } \\
\text { FODA }\end{array}$ & $\begin{array}{l}\text { F1. Facilidad en la otorgación de } \\
\text { créditos. } \\
\text { F2. Eficiente y eficaz sistema } \\
\text { contable. } \\
\text { F3. Variedad de servicios y } \\
\text { productos. } \\
\text { F4. Atención prioritaria a los } \\
\text { clientes de acuerdo a sus } \\
\text { necesidades. } \\
\text { F5. Moderno software para acceso } \\
\text { en línea. } \\
\text { F6. Know-How en tecnología micro } \\
\text { crediticia. } \\
\text { F7. Cartera automatizada }\end{array}$ & $\begin{array}{l}\text { D1. Sistema lento de atención al } \\
\text { cliente. } \\
\text { D2. Falta de programas de } \\
\text { educación financiera a } \\
\text { adolescentes, adultos mayores y } \\
\text { zonas rurales. } \\
\text { D3. Elevado costo de captación } \\
\text { respecto de tasa activa. } \\
\text { D4. Falta de planeamiento } \\
\text { estratégico y fortalecimiento } \\
\text { institucional. } \\
\text { D5. Limitaciones operativas para } \\
\text { atender una mayor cobertura local. }\end{array}$ \\
\hline Oportunidades & Estrategia FO & Estrategia DO \\
\hline $\begin{array}{l}\text { O1. Avance tecnológico y } \\
\text { ciberseguridad que optimiza los } \\
\text { servicios. } \\
\text { O2. Mejor posicionamiento de la } \\
\text { marca en el sector no } \\
\text { bancarizado. } \\
\text { O3. Acceso a créditos mediante } \\
\text { tarjetas de crédito. } \\
\text { O4. Desarrollo de los diversos } \\
\text { sectores económicos y sociales. } \\
\text { O5. Incremento de la cartera } \\
\text { crediticia. } \\
\text { O6.Menores costos en los } \\
\text { financiamientos. } \\
\text { O7.Alta demanda insatisfecha } \\
\text { de productos micro financieros. } \\
\text { O8.Crecimiento de las pequeñas } \\
\text { y medianas empresas. }\end{array}$ & $\begin{array}{l}\text { FO1. Fortalecer la cobertura local } \\
\text { aprovechando la atención } \\
\text { prioritaria a los clientes (F4), con el } \\
\text { fin de satisfacer la demanda de } \\
\text { créditos microfinancieros (O7). } \\
\text { FO2. Recurrir a la variedad de } \\
\text { productos y servicios (F3), para } \\
\text { incrementar la cartera crediticia } \\
\text { (O5). } \\
\text { FO3. Adaptar la facilidad en la } \\
\text { otorgación de créditos (F1), para } \\
\text { captar una mayor inversión de las } \\
\text { pequeñas y medianas empresas } \\
\text { (O8). } \\
\text { FO4. Aprovechar el uso de } \\
\text { sistemas informáticos modernos } \\
\text { para incrementar la operatividad } \\
\text { en línea. } \\
\text { FO5. Optimizar la cartera } \\
\text { automatizada (F7), para mejorar } \\
\text { los costos de financiamiento (O6) }\end{array}$ & $\begin{array}{l}\text { DO1. Aprovechar los avances } \\
\text { tecnológicos y las herramientas de } \\
\text { ciberseguridad (O1), para mitigar } \\
\text { los sistemas lentos de atención al } \\
\text { cliente (D1). } \\
\text { DO2.Regular el elevado costo de } \\
\text { captación (D3), teniendo en } \\
\text { cuenta el posicionamiento de la } \\
\text { marca en el sector no bancarizado } \\
\text { (O2). } \\
\text { DO3.Fortalecer los planes } \\
\text { estratégicos y de fortalecimiento } \\
\text { institucional (D4), para } \\
\text { incrementar el acceso a créditos } \\
\text { mediante tarjetas de crédito (O3). } \\
\text { DO4.Desarrollar programas de } \\
\text { educación financiera (D2), para } \\
\text { llegar a los diversos sectores } \\
\text { económicos y sociales (O4). }\end{array}$ \\
\hline
\end{tabular}


Revista Arbitrada Interdisciplinaria KOINONIA

Año V. Vol V. №10. Julio - Diciembre 2020

Hecho el depósito de Ley: FA2016000010

ISSN: 2542-3088

FUNDACIÓN KOINONIA (F.K). Santa Ana de Coro. Venezuela.

Eliana Michelle Ordóñez-Granda; Cecilia Ivonne Narváez-Zurita; Juan Carlos Erazo-Álvarez

\begin{tabular}{|c|c|c|}
\hline Amenazas & Estrategias FA & Estrategia DA \\
\hline 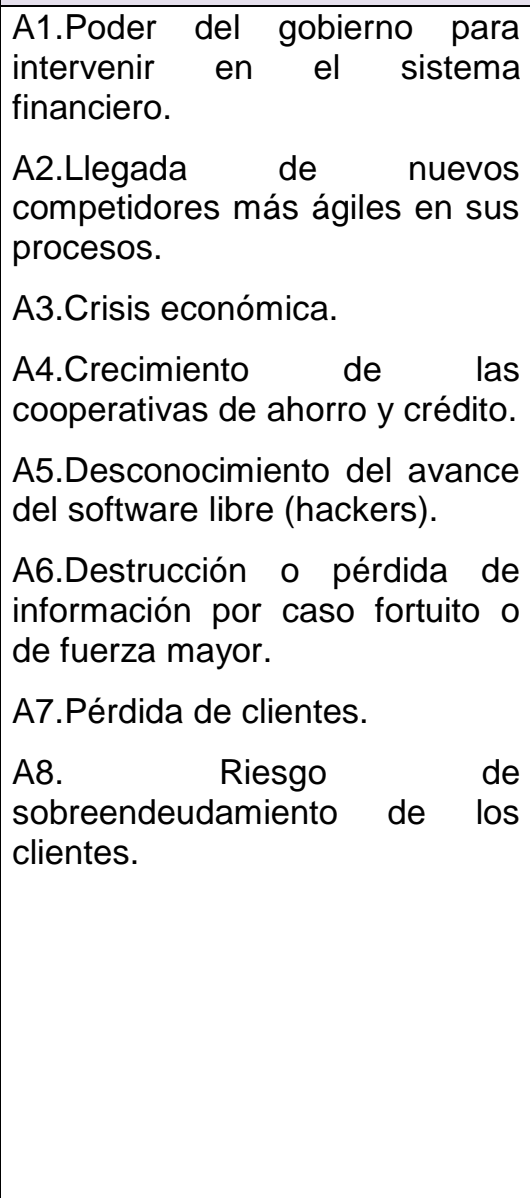 & 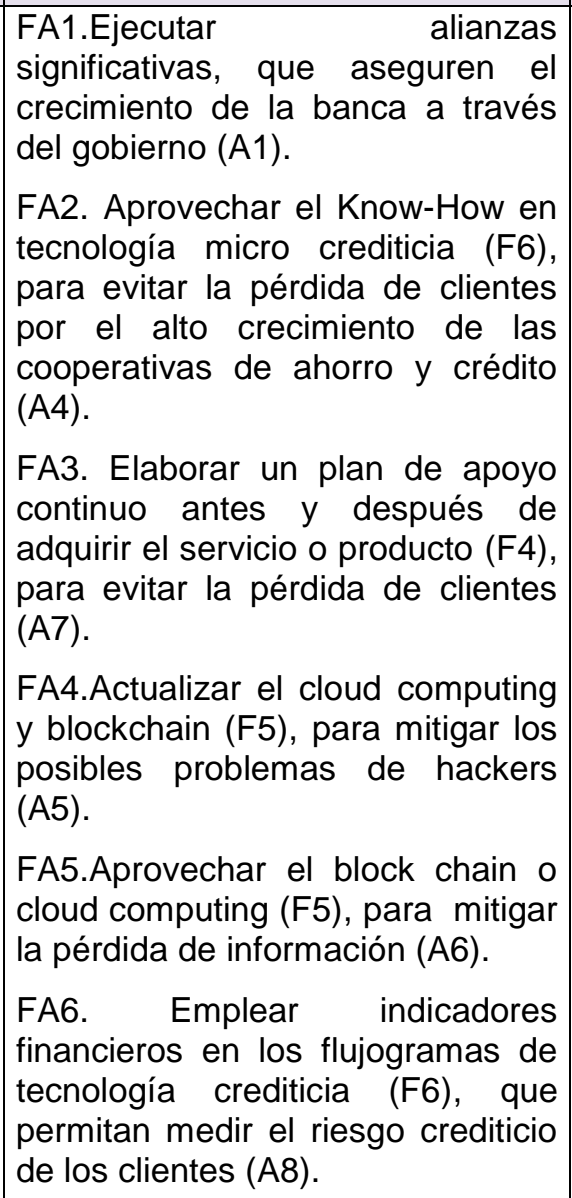 & $\begin{array}{l}\text { DA1. Realizar estudios de mercado } \\
\text { para las inversiones de alto riesgo } \\
\text { (D4), con el fin de afrontar } \\
\text { posibles crisis económicas (A3). } \\
\text { DA2. Fomentar la cadena de valor } \\
\text { empresarial que permita atender } \\
\text { una mayor cobertura local (D5), } \\
\text { para evitar la pérdida de clientes } \\
\text { (A7). } \\
\text { DA3.Elaborar un plan estratégico } \\
\text { (D4), que permita fortalecer y } \\
\text { optimizar los procesos internos } \\
\text { para obtener ventajas competitivas } \\
\text { (A2). } \\
\text { DA4.Desarrollar programas de } \\
\text { educación financiera que abarque } \\
\text { sectores rurales y que incluya a } \\
\text { adultos mayores (D2), con el fin de } \\
\text { evitar la pérdida de clientes (A7). } \\
\text { DA5. Analizar los métodos de } \\
\text { costeo que permitan a la } \\
\text { institución obtener costos } \\
\text { operativos acordes al servicio } \\
\text { (D3), y así obtener ventaja } \\
\text { competitiva dentro del mercado } \\
\text { financiero (A2). }\end{array}$ \\
\hline
\end{tabular}

Cuadro 1. Análisis cruzado FODA

Como segunda estrategia se procede a realizar un análisis de la cadena de valor, la misma que constituye una herramienta que analiza todas las actividades importantes que una empresa desarrolla para conocer el procedimiento de los costos. Al elaborar un modelo de cadena de valor se debe tener en cuenta la naturaleza del negocio bancario, diferenciando las actividades primarias y las de apoyo, en las instituciones bancarias la principal actividad constituye la colocación y captación de recursos de los clientes, el procesamiento de transacciones y la prestación de servicios. 
Para que la actividad primaria se ejecute con eficiencia, eficacia, requiere de actividades de apoyo como la administración general y la infraestructura la cual sirve de cimiento a toda la cadena; la contratación de personal asociado directa o indirectamente a cada categoría de la actividad primaria; también es indispensable la adquisición de programas informáticos, equipos, así como el mantenimiento de los mismos para que las transacciones se desarrollen con rapidez, seguridad, evitando el riesgo de sufrir hackeos de información para lo cual es importante que se desarrolle un adecuado control interno que permita resguardar los recursos para promover la eficiencia de los procesos, en base a lo antes mencionado se concluye que la cadena de valor representa una herramienta estratégica muy importante en el sistema bancario, porque define las actividades, los costos, las interrelaciones entre actividades y otras unidades de negocios, identificando así las fuentes de ventaja competitiva.
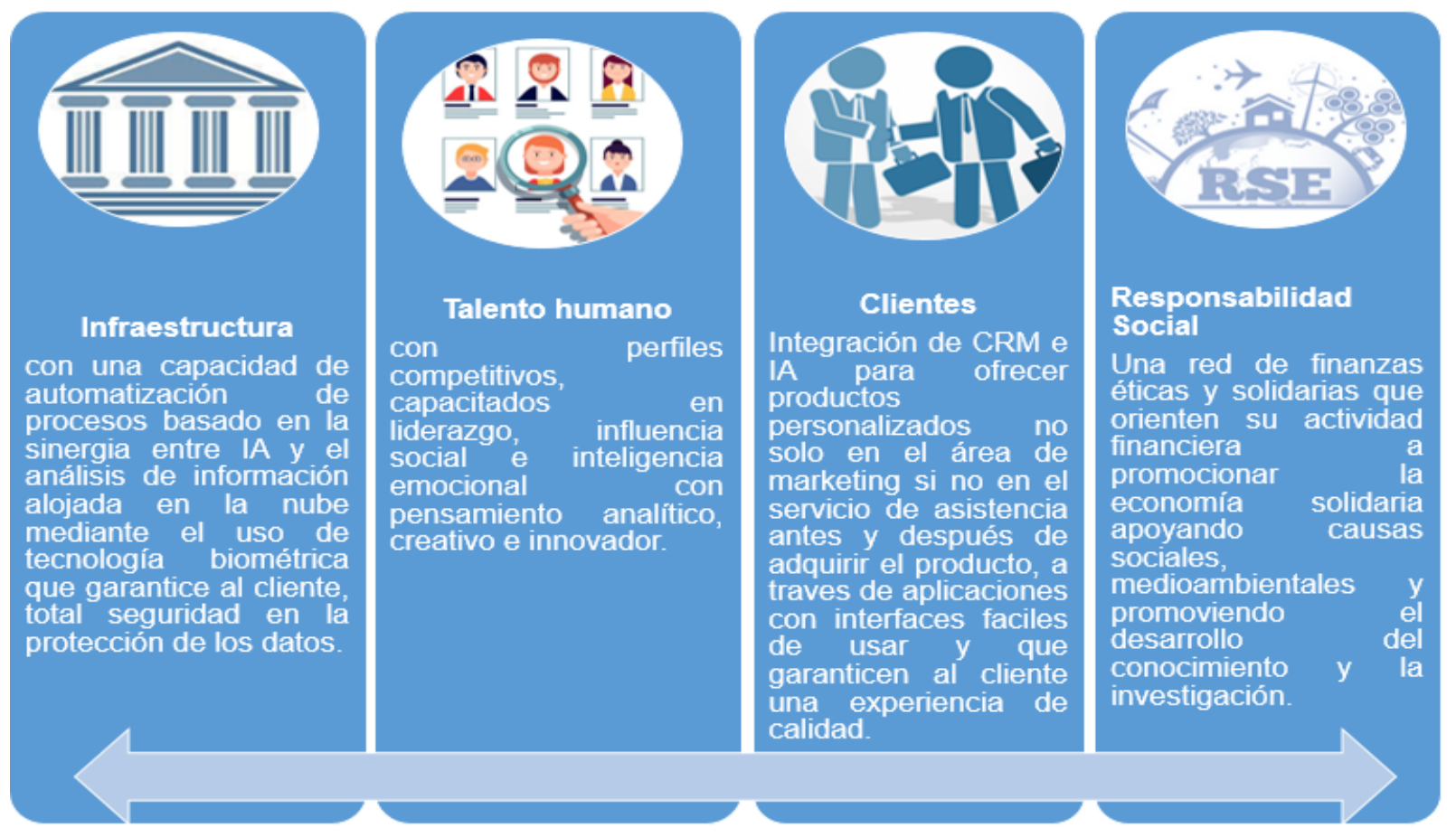

Figura 3. Cadena de valor. CRM: Customer relationship management, Gestión de la relación con los clientes IA: Inteligencia artificial 
Revista Arbitrada Interdisciplinaria KOINONIA

Año V. Vol V. №10. Julio - Diciembre 2020

Hecho el depósito de Ley: FA2016000010

ISSN: 2542-3088

FUNDACIÓN KOINONIA (F.K). Santa Ana de Coro. Venezuela.

Eliana Michelle Ordóñez-Granda; Cecilia Ivonne Narváez-Zurita; Juan Carlos Erazo-Álvarez

La tercera estrategia consiste en el diseño de un cuadro de mando integral, el cual permite medir la evolución de la actividad empresarial partiendo de la formulación de objetivos estratégicos, medidos en base a indicadores financieros y no financieros, estos a su vez permiten recopilar información periódica que sirve en la toma de decisiones y en el cumplimiento de las metas fijadas. La semaforización del cuadro de mando integral facilita a los altos mandos el seguimiento del plan estratégico, permitiendo identificar los valores que no cumplieron con lo esperado (color rojo) o los valores que han alcanzado la meta (color verde).

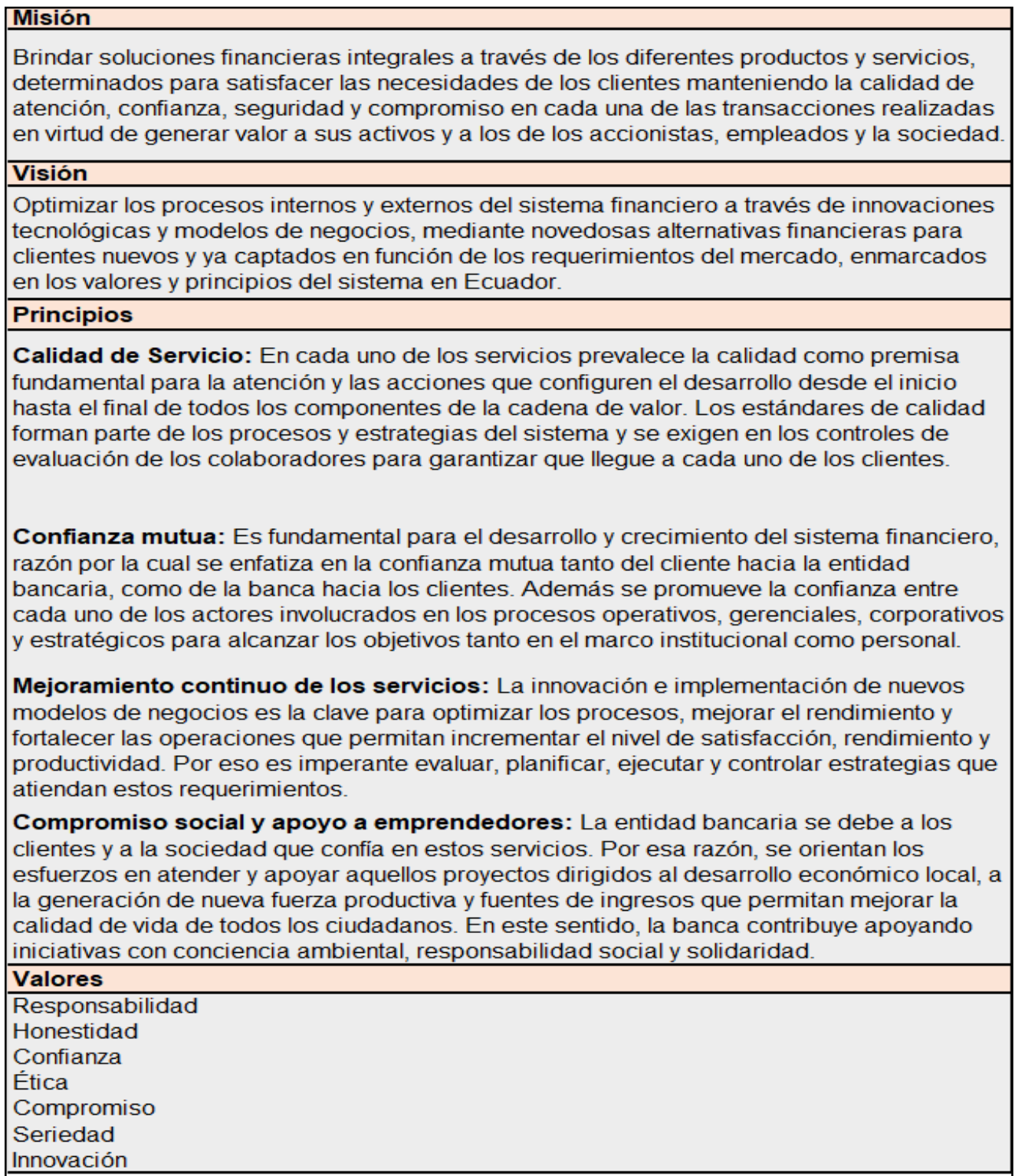




\begin{tabular}{|c|c|c|c|c|c|c|c|c|}
\hline \multirow{2}{*}{ Perspectiva } & \multirow{2}{*}{ Objetivo Estratégico } & \multicolumn{3}{|c|}{ Semaforización } & \multirow{2}{*}{ Metas } & \multirow{2}{*}{ Estrategias } & \multirow{2}{*}{ Indicadores } & \multirow{2}{*}{ Responsables } \\
\hline & & 0 & $\bigcirc$ & O & & & & \\
\hline \multirow{4}{*}{$\underset{\substack{\mathbb{N} \\
\text { I }}}{\stackrel{\text { I }}{I}}$} & $\begin{array}{l}\text { Minimizar el nivel de riesgo y } \\
\text { equilibrar la composición de } \\
\text { la cartera }\end{array}$ & $<10 \%$ & $10-25 \%$ & $>25 \%$ & $\begin{array}{r}\text { Reducir el riesgo } \\
\text { en un } 25 \% \text { anual }\end{array}$ & $\begin{array}{l}\text { Implementar modelos de negocios } \\
\text { financieros como el originate-to- } \\
\text { distribute para minimizar el riesgo de } \\
\text { crédito a través de instrumentos de } \\
\text { transferencia del riesgo de crédito } \\
\text { como fondos de pensiones, hedge } \\
\text { funds, mutual funds e incluso } \\
\text { empresas de seguro. }\end{array}$ & Nivel de riesgo & Finanzas \\
\hline & Generar nuevas inversiones & $<15 \%$ & $15-30 \%$ & $>30 \%$ & $\begin{array}{l}\text { Incrementar la } \\
\text { inversión de las } \\
\text { Pymes en un } \\
30 \% \text { anual }\end{array}$ & $\begin{array}{l}\text { Flexibilizar el otorgamiento de créditos } \\
\text { para pequeñas y medianas empresas } \\
\text { en virtud de incrementar las nuevas } \\
\text { inversiones de acuerdo a las politicas } \\
\text { emergentes de las NIIF -9 }\end{array}$ & Sostenibilidad & Finanzas \\
\hline & $\begin{array}{l}\text { Aumentar la cartera } \\
\text { crediticia }\end{array}$ & $<15 \%$ & $15-25 \%$ & $>25 \%$ & $\begin{array}{l}\text { Aumentar en un } \\
25 \% \\
\text { la entrada de } \\
\text { nuevos clientes }\end{array}$ & $\begin{array}{l}\text { Proponer una ampliada variedad de } \\
\text { productos y servicios para incrementar } \\
\text { la cartera crediticia en la banca } \\
\text { tradicional, automatizada, móvil y } \\
\text { online ante situaciones emergentes } \\
\text { como la provocada por el COVID-19 } \\
\text { durante la pandemia. }\end{array}$ & $\begin{array}{l}\text { Entradas de nuevos } \\
\text { clientes }\end{array}$ & Finanzas \\
\hline & $\begin{array}{l}\text { Incrementar el valor } \\
\text { financiero del segmento } \\
\text { bancario }\end{array}$ & $0 \%$ & $1-5 \%$ & $>5 \%$ & \begin{tabular}{l|} 
Incrementar un \\
$5 \%$ \\
anual el beneficio \\
neto generado \\
luego de la \\
inversión incial \\
en cada modelo \\
de negocio
\end{tabular} & $\begin{array}{l}\text { Implementar nuevos modelos de } \\
\text { negocio para revalorizar el sector } \\
\text { bancario al regular los costos de } \\
\text { captación aprovechando el } \\
\text { posicionamiento de la marca en el } \\
\text { sector no bancarizado. }\end{array}$ & $\begin{array}{l}\text { Beneficio sobre } \\
\text { fondos propios }\end{array}$ & Finanzas \\
\hline \multirow{5}{*}{ 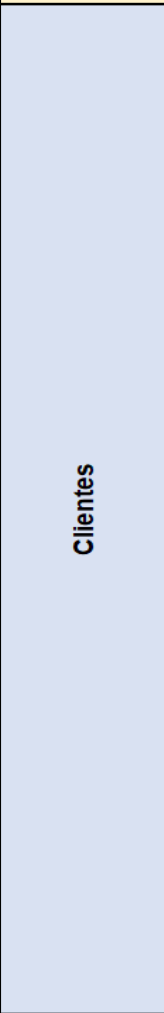 } & $\begin{array}{l}\text { Mejorar el nivel de } \\
\text { satisfacción del cliente }\end{array}$ & $<20 \%$ & $20-50 \%$ & $>50 \%$ & $\begin{array}{l}\text { Mejorar en un } \\
50 \% \text { el nivel de } \\
\text { satisfacción del } \\
\text { cliente }\end{array}$ & $\begin{array}{l}\text { Establecer nuevas estrategias de } \\
\text { atención el cliente en base a un } \\
\text { servicio de asesoramiento y valor } \\
\text { añadido para los clientes que se } \\
\text { fundamenta en un modelo de negocio } \\
\text { financiero centrado en servicios } \\
\text { personalizados y no sólo en el } \\
\text { producto que considere los gustos, } \\
\text { objetos y hábitos financieros del } \\
\text { cliente }\end{array}$ & Nivel de satisfacción & Operaciones \\
\hline & $\begin{array}{l}\text { Optimizar los canales de } \\
\text { respuesta y gestión de } \\
\text { soluciones para los clientes }\end{array}$ & $<30$ & $30-70 \%$ & $>70 \%$ & \begin{tabular}{|l|} 
Minimizar el \\
número de \\
reclamos sin \\
respuestas en un \\
$70 \%$ \\
\end{tabular} & $\begin{array}{l}\text { Crear, fortalecer y actualizar los } \\
\text { canales de respuesta a los } \\
\text { requerimientos, reclamos y quejas de } \\
\text { los clientes en cualquiera de las áreas } \\
\text { para incrementar el número de } \\
\text { soluciones a través de las diferentes } \\
\text { innovaciones tecnológicas y } \\
\text { formativas en atención al cliente }\end{array}$ & $\begin{array}{l}\text { Soluciones } \\
\text { alcanzadas }\end{array}$ & Operaciones \\
\hline & $\begin{array}{l}\text { Mejorar la imagen } \\
\text { institucional a través de la } \\
\text { percepción de la marca }\end{array}$ & $<20 \%$ & $20-30 \%$ & $>30 \%$ & \begin{tabular}{|l|} 
Alcanzar un $30 \%$ \\
de preferencia \\
en el mercado
\end{tabular} & \begin{tabular}{|l|} 
Rediseñar el modelo de banca \\
tradicional a nuevos modelos de \\
negocios como la banca digital y \\
banca móvil sostenible, que optimice \\
sus interacciones con el cliente, sus \\
productos, servicios, sus procesos y \\
sus datos alrededor de las tecnologias \\
digitales, permitiendo disminuir costos \\
de servicios y enriquecer la \\
experiencia del cliente.
\end{tabular} & Imagen & Operaciones \\
\hline & $\begin{array}{l}\text { Incrementar la fidelidad de } \\
\text { los clientes }\end{array}$ & $<40 \%$ & $40-60 \%$ & $>60 \%$ & $\begin{array}{l}\text { Nivel de fidelidad } \\
>60 \% \text { de los } \\
\text { clientes }\end{array}$ & $\begin{array}{l}\text { Elaborar un plan de servicio al cliente } \\
\text { antes y después de adquirir el servicio } \\
\text { o producto para mantener la fidelidad } \\
\text { de clientes. }\end{array}$ & Nivel de fidelidad & Operaciones \\
\hline & $\begin{array}{l}\text { Optimizar las politicas de } \\
\text { atención al cliente y } \\
\text { procedimientos }\end{array}$ & $<30 \%$ & $30-100 \%$ & $100 \%$ & $\begin{array}{l}\text { Agregar valor } \\
\text { en todas las } \\
\text { unidades de la } \\
\text { cadena de valor } \\
(100 \%)\end{array}$ & $\begin{array}{l}\text { Capacitar al personal para optimizar el } \\
\text { manejo de recursos y atención al } \\
\text { cliente a través de cursos y politicas } \\
\text { de atención y procedimientos en toda } \\
\text { la cadena de valor empresarial para } \\
\text { agregar valor al servicio en virtud de } \\
\text { mantener al cliente y su nivel de } \\
\text { satisfacción. }\end{array}$ & Valor agregado & Operaciones \\
\hline
\end{tabular}


Revista Arbitrada Interdisciplinaria KOINONIA

Año V. Vol V. №10. Julio - Diciembre 2020

Hecho el depósito de Ley: FA2016000010

ISSN: 2542-3088

FUNDACIÓN KOINONIA (F.K). Santa Ana de Coro. Venezuela.

Eliana Michelle Ordóñez-Granda; Cecilia Ivonne Narváez-Zurita; Juan Carlos Erazo-Álvarez

\begin{tabular}{|c|c|c|c|c|c|c|c|c|}
\hline \multirow{5}{*}{ 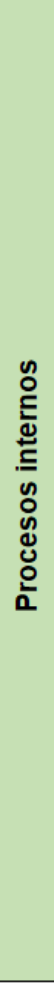 } & $\begin{array}{l}\text { Planificar estrategias de } \\
\text { mitigación de riesgos }\end{array}$ & $<30 \%$ & $30-40 \%$ & $>40 \%$ & $\begin{array}{l}\text { Minimizar en un } \\
40 \% \text { anual los } \\
\text { posibles riesgos } \\
\text { crediticios }\end{array}$ & $\begin{array}{l}\text { Realizar estudios de mercado para las } \\
\text { inversiones de alto riesgo con el fin de } \\
\text { afrontar posibles crisis económicas. }\end{array}$ & Nivel de riesgos & Gerente \\
\hline & $\begin{array}{l}\text { Optimizar el sistema de } \\
\text { banca virtual y automatizada. }\end{array}$ & $>20$ & $20-15$ & $<15$ & $<15$ anual & $\begin{array}{l}\text { Aprovechar los avances tecnológicos y } \\
\text { las herramientas de ciberseguridad } \\
\text { para mitigar los sistemas lentos de } \\
\text { atención al cliente e incrementar la } \\
\text { cartera automatizada para mejorar } \\
\text { costos de financiamiento. }\end{array}$ & Fallos en el sistema & Gerente \\
\hline & $\begin{array}{l}\text { Maximizar la cadena de } \\
\text { valor }\end{array}$ & $<30 \%$ & $30-70 \%$ & $>70 \%$ & $\begin{array}{l}\text { Minimizar las } \\
\text { interrupciones } \\
\text { internas en un } \\
70 \%\end{array}$ & $\begin{array}{l}\text { Modernizar la infraestructura operativa } \\
\text { a traves de la contratación de } \\
\text { proveedores externos que esten } \\
\text { integrados para optimizar la cadena } \\
\text { de valor, con la gestión de activos } \\
\text { tecnológicos que automaticen los } \\
\text { procesos y minimicen las } \\
\text { interrupciones internas. }\end{array}$ & $\begin{array}{l}\text { Interrupciones } \\
\text { internas }\end{array}$ & Gerente \\
\hline & $\begin{array}{l}\text { Implementar procesos y } \\
\text { tecnologia innovadoras para } \\
\text { enfrentar la competencia }\end{array}$ & 0 & Hasta 2 & $>2$ & \begin{tabular}{|l|} 
Incorporar 2 \\
innovaciones \\
tecnológicas anual
\end{tabular} & $\begin{array}{l}\text { Incorporar innovaciones tecnológicas } \\
\text { en materia microcrediticia para evitar } \\
\text { la pérdida de clientes por el } \\
\text { incremento de las cooperativas de } \\
\text { ahorro y crédito y mantengan la ventaja } \\
\text { competitiva. }\end{array}$ & $\begin{array}{l}\text { Innovaciones } \\
\text { tecnológicas } \\
\text { incorpopradas }\end{array}$ & Gerente \\
\hline & $\begin{array}{l}\text { Establecer alianzas } \\
\text { estratégicas innovadoras } \\
\text { con terceros no } \\
\text { gubernamentales. }\end{array}$ & $<3$ & \begin{tabular}{|l} 
Entre 3 \\
y 5
\end{tabular} & $>5$ & 5 alianzas anuales & $\begin{array}{l}\text { Aplicar un modelo de negocio de } \\
\text { plataforma en base a alianzas } \\
\text { estratégicas con los fintech para } \\
\text { comercializar productos financieros y } \\
\text { no financieros donde el banco sea } \\
\text { proveedor de servicios especializados } \\
\text { entre clientes, compradores y } \\
\text { vendedores. }\end{array}$ & Número de alianzas & Gerente \\
\hline \multirow{3}{*}{ 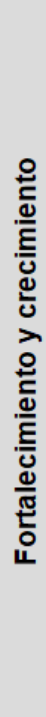 } & $\begin{array}{l}\text { Actualizar el inventario de } \\
\text { competencias para } \\
\text { formaciones continuas }\end{array}$ & $>5$ & $5-0$ & & $0 \begin{array}{l}\text { Reducir a } 0 \text { las } \\
\text { debilidades de } \\
\text { desempeño }\end{array}$ & $\begin{array}{l}\text { Realizar una evaluación de } \\
\text { desempeño y un inventario de } \\
\text { competencias que permita identificar } \\
\text { las fortalezas y debilidades del } \\
\text { personal que permita planificar un } \\
\text { cronograma de formación continua en } \\
\text { base a las habilidades y } \\
\text { conocimientos que exigen } \\
\text { capacitación. }\end{array}$ & \begin{tabular}{|c|} 
Debilidades y \\
fortalezas \\
identificadas en las \\
competencias y \\
habilidades de los \\
empleados
\end{tabular} & Recursos Humanos \\
\hline & $\begin{array}{l}\text { Mejorar la seguridad } \\
\text { tecnológica del sistema } \\
\text { financiero }\end{array}$ & $<100$ & $100-160$ & $>160$ & 160 horas mensual & $\begin{array}{l}\text { Actualizar los conocimientos de los } \\
\text { ingenieros e informáticos en materia } \\
\text { de cloud computing y blockchain para } \\
\text { mitigar los posibles problemas de } \\
\text { hackers y mitigar los riesgos mediante } \\
\text { la aplicación de soluciones de } \\
\text { verificación de firmas, autentificación } \\
\text { facial, identificación biometrica por } \\
\text { medio de la voz. }\end{array}$ & $\begin{array}{c}\text { Horas de formación } \\
\text { a ingenieros e } \\
\text { informáticos }\end{array}$ & Recursos Humanos \\
\hline & $\begin{array}{l}\text { Formar a los actores de los } \\
\text { diferentes sectores } \\
\text { socioeconómicos }\end{array}$ & $<500$ & $500-800$ & $>800$ & $\begin{array}{l}800 \text { horas de } \\
\text { formación anual }\end{array}$ & $\begin{array}{l}\text { Desarrollar programas de educación } \\
\text { financiera a través de las TIC's para } \\
\text { llegar a los diversos sectores } \\
\text { económicos y sociales en función de } \\
\text { captar y promover nuevos clientes. }\end{array}$ & $\begin{array}{c}\text { Horas de formación } \\
\text { por sector }\end{array}$ & Recursos Humanos \\
\hline
\end{tabular}

Figura 4. Cuadro de mando integral. Fuente: (González-Bustos, Narváez-Zurita \& Erazo-Álvarez, 2020). 


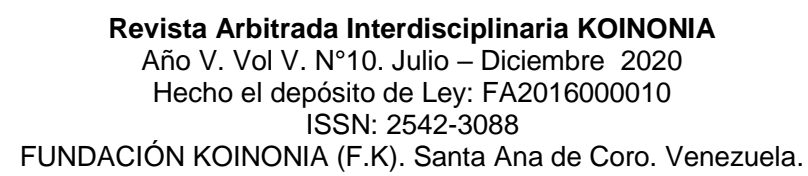

Eliana Michelle Ordóñez-Granda; Cecilia Ivonne Narváez-Zurita; Juan Carlos Erazo-Álvarez

\section{DISCUSIÓN}

El sistema financiero tiene un papel fundamental en el desarrollo de la economía mundial, de ahí la importancia de reconocer cada uno de los elementos que lo componen, así como los factores que inciden en la dinámica del sector y su crecimiento. Esta investigación, se orientó al reconocimiento del sistema financiero en Ecuador considerando la evolución histórica que ha tenido en el país y las múltiples funciones que éste cumple en el desarrollo económico y productivo local.

Esta característica del sistema financiero, exige el uso de herramientas innovadoras que se han desarrollado a la par del servicio y modelos de negocios que aportan al financiamiento de la banca porque reducen significativamente los costos de infraestructura para generar mayor valor al sector a través del mejoramiento de los servicios, la accesibilidad y la flexibilidad que le permita ajustarse a las dinámicas del cliente en virtud de alcanzar una mayor inclusión bancaria en sectores no cubiertos e incrementar su ventaja competitiva (Banco Central del Ecuador, 2012).

Entre los hallazgos de este estudio, destaca el reconocimiento de la colocación de créditos, las inversiones y la cartera de crédito como giro de negocio de la banca ecuatoriana que se ajusta a las directrices de la Superintendencia de Bancos y Seguros (Superintendencia de Bancos y Seguros, 2017); además, el 100\% de las instituciones consultadas señalan la importancia de la evaluación del desempeño y la planificación estratégica para cumplir con sus objetivos.

En este orden de ideas, el $86 \%$ de estas instituciones han incursionado en la banca virtual, lo que evidencia que existe la disposición de utilizar estos recursos para agregar valor a sus cadenas, mejorar el servicio y optimizar los procesos a través de modelos de negocios que involucren este tipo de innovaciones.

En consecuencia, la propuesta realizada en esta investigación atiende tanto a las características del sistema financiero ecuatoriano como a la realidad actual en la que se desarrolla, donde se han generado gran cantidad de cambios y transformaciones en diferentes sectores productivos. 


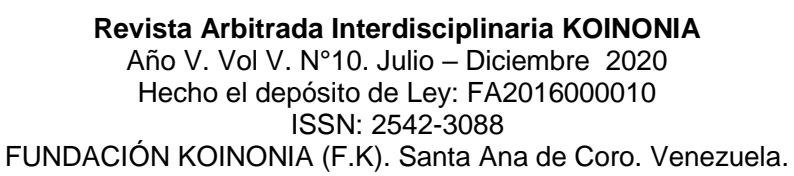

Eliana Michelle Ordóñez-Granda; Cecilia Ivonne Narváez-Zurita; Juan Carlos Erazo-Álvarez

De igual manera la propuesta busca mitigar los riesgos que se han generado en la actualidad a consecuencia de la pandemia mundial, por cuanto este fenómeno ha reducido de manera sustancial la demanda de bienes y servicios afectando directamente a los hogares y al sistema financiero, en consecuencia, se plantean estrategias para que los bancos sigan prestando sus servicios de intermediación con la calidad debida y el aseguramiento adecuado de la información.

En virtud de ello, la propuesta se orienta a establecer nuevos modelos de negocios para el sector financiero y el uso de herramientas innovadoras para promover la inclusión financiera considerando estrategias que implican la virtualización como plataforma para el desarrollo de las relaciones económicas y sociales como las fintech que permiten la bancarización en las economías en desarrollo por utilizar la conectividad como plataforma de innovación de los servicios financieros (Banco de $D$ esarrollo de América Latina, 2016).

Asimismo, modelos como el originate-to-distribute o conocido como originar para distribuir es otro de los modelos de negocios que buscan minimizar los riesgos a través de las transferencias de crédito que permiten enfrentar los desafíos de la banca en función de alcanzar las metas establecidas en la planificación estratégica, entendiendo que, aunque existan crisis y emergencias como las derivadas del COVID-19, es preciso atender a las necesidades del sector que exigen estrategias flexibles y efectivas orientadas al cumplimiento de la filosofía de gestión.

\section{FINANCIAMIENTO}

No monetario. 


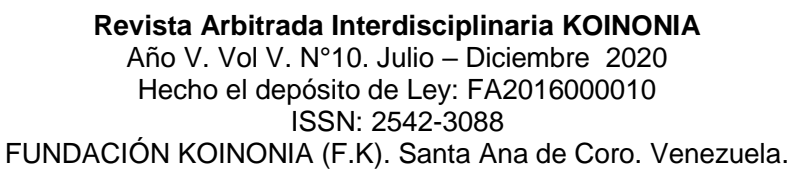

Eliana Michelle Ordóñez-Granda; Cecilia Ivonne Narváez-Zurita; Juan Carlos Erazo-Álvarez

\section{AGRADECIMIENTO}

A las autoridades y al personal administrativo instituciones financieras localizados en la ciudad de Cuenca (Banco del Austro, Banco Guayaquil, Banco Pacífico, Banco Pichincha, Coop. Jardín Azuayo); quienes facilitaron toda la información necesaria para el desarrollo de esta investigación.

\section{REFERENCIAS CONSULTADAS}

Acosta-Véliz, M, Coronel-Pérez, V, \& Bermúdez-Gallegos, C. (2018). Modelo de negocio de inclusión financiera a través de corresponsales no bancarios en la ciudad de Guayaquil, Ecuador. [Business model of financial inclusion through non-banking correspondents in the city of Guayaquil, Ecuador]. Revista Universidad y Sociedad, 10(3), 263-268. Recuperado de https://n9.cl/0wqz

Banco de Desarrollo de América Latina (2016). La revolución de las empresas FinTech y el futuro de la Banca. Disrupción tecnológica en el sector financiero. [The FinTech business revolution and the future of banking. Technological disruption in the financial sector]. Recuperado de https://n9.cl/w0h8

Banco Central del Ecuador. (2012). Inclusión financiera aproximaciones teóricas y prácticas. [Financial inclusion, theoretical and practical approaches]. Recuperado de https://n9.cl/9c5s

Birochi, R, \& Pozzebon, M. (2016). Improving financial inclusion: towards a critical financial education framework. [Mejora de la inclusión financiera: hacia un marco crítico de educación financiera]. Revista de Administração de Empresas, 56(3), 266-287. https://doi.org/10.1590/S0034-759020160302

Cáceres-Larreátegui, A., Torres-Mejía, S., \& Briones-Arteaga, B. (2019). Gestión de la calidad y su incidencia administrativa financiera en las instituciones de Educación Superior. [Quality management and its financial administrative impact in Higher Education institutions].CIENCIAMATRIA, 6(10), 478-488. https://doi.org/10.35381/cm.v6i10.152 


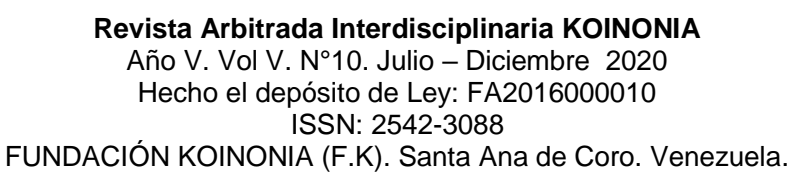

Eliana Michelle Ordóñez-Granda; Cecilia Ivonne Narváez-Zurita; Juan Carlos Erazo-Álvarez

Cepeda-Cobos, J. (2014). Impacto de los corresponsales no bancarios (banco del barrio Guayaquil; mi vecino Pichincha; tu banco aquí Pacífico. En el índice de bancarización del Ecuador: 2008-2013. [Impact of non-bank correspondents (Guayaquil neighborhood bank; my neighbor Pichincha; your bank here Pacífico. In the bank penetration index of Ecuador: 2008-2013]. Recuperado de https://n9.cl/ggam

De-Olloqui, F., Andrade, G., \& Herrera, D. (2015). Inclusión finanicera en América Latina y el Caribe. [Financial inclusion in Latin America and the Caribbean]. Recuperado de https://n9.cl/fjuw

González-Bustos, J. P., Narváez-Zurita, C. I., \& Erazo-Álvarez, J. C. (2020). La gestión de responsabilidad social de las cooperativas de ahorro y crédito de la provincia del Azuay y su retorno financiero. [The management of social responsibility of the savings and credit cooperatives in Azuay province and their financial return]. Dominio de las Ciencias, 04-33. http://dx.doi.org/10.23857/dc.v6i1.1135

Guerra, D. (2015). Plan de Marketing para los corresponsales no bancarios del Banco del Pichincha en el Distrito Metropolitano de Quito. [Marketing Plan for non-bank correspondents of Banco del Pichincha in the Metropolitan District of Quito]. Recuperado de https://n9.cl/xghx

Hernández, R., Fernández, C., Baptista, P. (2014). Metodología de la Investigación. [Investigation methodology]. México: Editorial Mc - Graw - Hill Interamericana. Sexta edición.

Instituto Nacional de Estadística y Censos. (2013). INEC presenta resultados de la Encuesta de Ingresos y Gastos. [INEC presents results of the Income and Expenses Survey]. Recuperado de https://n9.cl/51gm

Instituto Nacional de Estadística y Censos. (2017). Estadísticas monetarias y financieras. [Monetary and financial statistics]. Recuperado de https://n9.cl/d6k3

Kumar, A., Nair , A., Parsons, A., \& Urdapilleta, E. (2006). Expanding Bank Outreach through Retail Partnerships. Correspondent Banking In Brazil. [Expansión del alcance bancario a través de asociaciones minoristas. Banca corresponsal en Brasil]. Recuperado de https://n9.cl/phma 


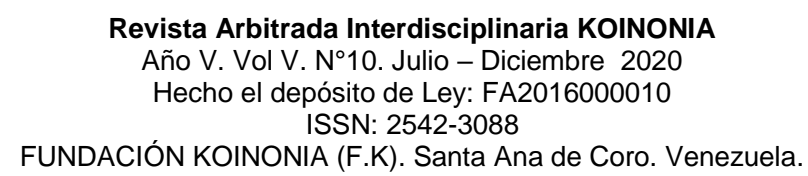

Eliana Michelle Ordóñez-Granda; Cecilia Ivonne Narváez-Zurita; Juan Carlos Erazo-Álvarez

Leonardi, P., Bailey, D. E., Diniz, E. H., Sholler, D., \& Nardi, B. A. (2016). Multiplex appropriation in complex systems implementation: the case of Brazil's correspondent banking system. [Asignación múltiple en la implementación de sistemas complejos: el caso del sistema de corresponsalía bancaria de Brasil]. Recuperado de https://n9.cl/ub9i

Llistar, D. (2002). Observatori del deute en la globalitzacio. [Debt observatory in globalization]. Cátedra Unesco a la UPC.

Méndez, M. (2010). Corresponsables no banacarios en Ecuador. [Non-bank correspondents in Ecuador]. Recuperado de https://n9.cl/evkjm

Patiño, M. (2014). Para qué sirven los instrumentos financieros. [What are financial instruments for?]. Recuperado de https://n9.cl/dh49

Peña, P., \& Vázquez, A. (2012). El impacto de los corresponsables bancarios en la inclusión financiera:una primera evaluación. [The impact of bank co-managers on financial inclusion: a first evaluation]. Estudios Económicos CNBV, Vol. 1; 195215. Recuperado de https://n9.cl/9xlvq

Rodríguez, L. (2017). La inclusión financiera como practica de responsabilidad social en entidades bancarias de la ciudad de Bogotá D.C para estratos 1 y 2. [Financial inclusion as a practice of social responsibility for strata 1 and 2 in banks in Bogotá D.C,]. Recuperado de https://n9.cl/kr6u

Romero, B. (2015). La Estructura del Sistema Financiero Ecuatoriano. [The Structure of the Ecuadorian Financial System]. Recuperado de https://n9.cl/lewca

Superintendecia de Bancos y Seguros del Ecuador. (2011). Normas generales para las instituciones del sistema finanicero. [General rules for the institutions of the financial system]. Recuperado de https://n9.cl/ygfx

Superintendencia de Bancos. (2017). Mecanismo de inclusión financiera "IF" en el Ecuador [Financial inclusion mechanism "FI" in Ecuador]. Recuperado de https://n9.cl/jw08

Superintendencia de Bancos. (2018). Comportamiento financiero: banco de desarrollo. Período Diciembre 2017 - Diciembre 2018. [Financial behavior: development bank. Period December 2017 - December 2018]. Recuperado de https://n9.cl/xve8 


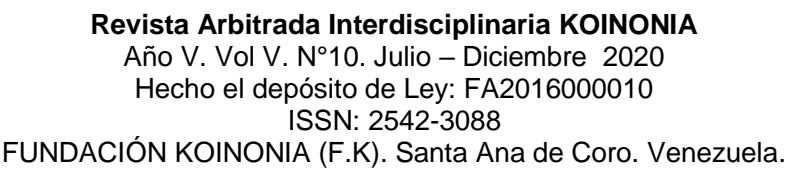

Eliana Michelle Ordóñez-Granda; Cecilia Ivonne Narváez-Zurita; Juan Carlos Erazo-Álvarez

Taimal, E. (2016). Informe Sectorial. Ecuador: sector bancario. [Sector Report. Ecuador: banking sector]. Recuperado de https://n9.cl/e1jh

Trujillo, A. (2014). NIIF para PYMES: manejo de los instrumentos financieros aplicación de los instrumentos financieros para las empresas PYMES. [IFRS for SMEs: administration and application of financial instruments for SME companies]. Recuperado de https://n9.cl/9uhz

Zhañay-Soliz, O., Erazo-Álvarez, J., \& Narváez -Zurita, C. (2019). Modelo de Auditoria de Sistemas de Información para las Cooperativas de ahorro y crédito del segmento 1, 2, y 3, de la ciudad de Cuenca. [Information Systems Audit Model for Savings and Credit Cooperatives of the Segment 1, 2, and 3, in Cuenca city]. CIENCIAMATRIA, 5(1), 361-393. https://doi.org/10.35381/cm.v5i1.271

C2020 por los autores. Este artículo es de acceso abierto y distribuido según los términos y condiciones de la licencia Creative Commons Atribución-NoComercial-Compartirlgual 4.0 Internacional (CC BY-NC-SA 4.0)

(https://creativecommons.org/licenses/by-nc-sa/4.0/). 